\title{
pH Dependent Synthesis And Characterization of Bismuth Molybdate Nanostructure for Photocatalysis Degradation of Organic Pollutants
}

Huda N. Abid ( $\sim$ hudah3438@gmail.com )

University of Technology

\section{Amar Al-keisy}

University of Technology Nanotechnology and Advanced Materials Research Center https://orcid.org/0000-0003-29839689

Duha S. Ahmed

University of Technology

Ammar T. Salih

University of Technology Nanotechnology and Advanced Materials Research Center

Abbas Khammas

University of Technology Nanotechnology and Advanced Materials Research Center

\section{Research Article}

Keywords: Bi2MoO6, Photocatalytic degradation, Visible Light, Hydrothermal method.

Posted Date: September 7th, 2021

DOI: https://doi.org/10.21203/rs.3.rs-752076/v1

License: (9) (1) This work is licensed under a Creative Commons Attribution 4.0 International License. Read Full License

Version of Record: A version of this preprint was published at Environmental Science and Pollution Research on January 23rd, 2022. See the published version at https://doi.org/10.1007/s11356-021-18064-3. 


\section{Abstract}

Bismuth Molybdate nanostructures were synthesized using a simple hydrothermal method at varied $\mathrm{pH}(2,4,6,8$, and 10$)$ for $15 \mathrm{~h}$ at $180^{\circ}$. The results show that the $\mathrm{pH}$ precursor solutions have a significant impact on the morphology, phase formations and photocatalytic activity. The FESEM observations and XRD analysis, at low $\mathrm{PH}$ level, $\mathrm{Bi}_{2} \mathrm{MoO}_{6}$ nanoplates have formed while gradually convert to $\mathrm{Bi}_{2} \mathrm{MoO}_{6}$ spherical nanoparticle at high $\mathrm{PH}$ level. The optical absorption study demonstrated that $\mathrm{Bi}_{2} \mathrm{MoO}_{6}$ nanoplates absorbed visible light, but that there was a blue shift when compared to the cubic $\mathrm{Bi}_{4} \mathrm{MoO}_{9}$ structures. Photocatalytic activity revealed that nanoplates in $\mathrm{pH}=4$ sample has excellent photocatalytic activity for degradation of rhodamine (RhB), methylene orange (MO) and phenol under visible- light irradiation $(\lambda>400 \mathrm{~nm})$. The most important point is photodegradation $90 \%$ of phenol within $300 \mathrm{~min}$.

\section{Introduction}

Photocatalysis procedure under solar light has exceptionally attracted and interested of researchers because it has the ability of splitting the water molecules and decomposing the organic contaminants (Miao, Pan et al. 2013, Phuruangrat, Putdum et al. 2015, Peng, Ye et al. 2021, Ramasamy, Jeyadharmarajan et al. 2021). Photocatalysis based on visible light has accounted for roughly $43 \%$ of solar energy, while UV radiation has accounted for just $5 \%$. As a result, the development of new semiconductor-based materials is important in the field of Photocatalysis (Zhang, Wang et al. 2010). Various semiconductor-based photocatalysts, such as Bi-based (Dai, Qin et al. 2016), Ag-based (Du, Yang et al. 2021), In-based (Guo, Zhang et al. 2014), Ti-based (Guo, Zhou et al. 2019), and Cu-based (Luo, Steier et al. 2016), have been extensively studied during the last decade which related to chemical stability, high oxidized activity, non-toxicity and low prices (Asahi, Morikawa et al. 2001). Thoroughly traditional studies of $\mathrm{TiO}_{2}$ demonstrated its excellent activities and stabilities, but the technical implementation appeared to be constrained by certain parameters(Nakata and Fujishima 2012). Although the $\mathrm{TiO}_{2}$-based materials are represented the most important photocatalysts, the band gap of titania (anatase) is $3.2 \mathrm{eV}$ and it absorbs only UV light $(<450 \mathrm{~nm})$ which lower the efficacy of using Solar energy and accounts for about $4 \%$ of the sunlight (Madhusudan, Yu et al. 2012, Liang, Yang et al. 2013, Phuruangrat, Jitrou et al. 2013, Xiao, Hu et al. 2013, Wang, Zheng et al. 2016). $\mathrm{Cu}_{2} \mathrm{O}$ is excellent for water splitting due to own conduction band negatively enough to reduction $\mathrm{H}_{2} \mathrm{O}$ to $\mathrm{H}_{2}$, however, it has high electron-hole pair recombination rate (Wang, Zheng et al. 2016). Recently, photocatalysts-based bismuth oxide for visible light activity include bismuth oxide (Xiao, Hu et al. 2013), bismuth molybdate (Phuruangrat, Jitrou et al. 2013), bismuth tungstate [9], bismuth subcarbonate (Madhusudan, Yu et al. 2012), and bismuth vanadate (Rahman, Haque et al. 2019), have extraordinarily studied to photodegradation due to own excellent activity.

$\mathrm{Bi}_{2} \mathrm{MoO}_{6}$ was discovered to be particularly interesting due to its physical properties for use as a dielectric material, gas sensors, ionic conductors, luminescent material, and photocatalyst. Because the $\mathrm{Bi}_{2} \mathrm{MoO}_{6}$ has deep valence band therefore it has strong oxidative potential as well as reductive potential in conduction band. The strong oxidative potential can directly degrade organic pollutants while the electron in conduction band produce superoxide (Galván, Castillón et al. 1999, Miao, Pan et al. 2013).

The $\mathrm{Bi}_{2} \mathrm{MoO}_{6}$, as an n-type semiconductor, with 2.6-2.9 eV, has been attracted for many previous papers as excellent photocatalyst (Zhao, Liu et al. 2016). the crystal structure is layers of perovskite $\left(\mathrm{A}_{m-1} \mathrm{~B}_{m} \mathrm{O}_{3 m+1}\right)$ and bismuth oxide $\left(\mathrm{Bi}_{2} \mathrm{O}_{2}\right.$

$\left.{ }^{2+}\right)$, which are stacked together and have excellent photocatalytic activity when exposed to visible light because it has spatial photoinduced charge separation, which have been extensively investigated as potential catalysts for accelerating the decomposition of organic pollutants such as phenol, rhodamine B (RhB), methylene orange (MO) n-butene, and methylene blue by converting them into $\mathrm{CO}_{2}$ and $\mathrm{H}_{2} \mathrm{O}$ via photogenerated electron-hole pairs (Dumrongrojthanath, Thongtem et al. 2015, Meng and Zhang 2017).

The $\mathrm{pH}$-synthesis solution, in particularly Bismuth compound, is considered having significant influence on formation the composition and morphologies of the photocatalysis(Deng, Wang et al. 2005, Jin, Ye et al. 2015). Based on above details, we 
have adopted strategy to control the form and morphology of Bismuth Molybdate by adjust $\mathrm{pH}$, the reaction has carried out by hydrothermal and the photocatalytic activities were tested for photodegrade dye and phenol.

\section{Experimental}

\subsection{Experimental Procedures}

In this study, 1 mmole of sodium molybdate $\left(\mathrm{Na}_{2} \mathrm{MoO}_{4}\right)$ was dissolved in $10 \mathrm{~mL}$ deionized water and 2 mmole of bismuth nitrate $\left(\mathrm{Bi}\left(\mathrm{NO}_{3}\right)_{3}\right)$ were dissolved in $10 \mathrm{~mL} \mathrm{HNO}_{4}$. Subsequently, these two solutions were mixed together under vigorous stirring, then 2 mmole $\mathrm{NaOH}$ was added using drop casting technique to them until the mixture was reach to the desired $\mathrm{pH}$. The mixture was stirred for another $1 \mathrm{~h}$ and transferred into Teflon-lined stainless steel autoclaves of $50 \mathrm{~mL}$ capacity. The hydrothermal process was carried out at $180^{\circ} \mathrm{C}$ for $15 \mathrm{~h}$ and the autoclaves were left to cool down to room temperature. Finally, the resulted precipitation was filtered and washed with deionized water and ethanol for several times, and dried in oven at $60^{\circ} \mathrm{C}$ for $24 \mathrm{~h}$. The procedure was repeated at different values of $\mathrm{pH}$ and studies the effect of $\mathrm{pH}$ on resulted samples.

\subsection{Characterization}

X-Ray diffraction (Shimadzu X-ray diffraction 6000) analysis with Cu K radiation (1.54060 A) at $40 \mathrm{kV}$ and $30 \mathrm{~mA}$ was used to determine the phase and composition of the as-prepared samples, with the $2 \theta$ ranging from $20^{\circ}$ to $70^{\circ}$. The FieldEmission Electron Microscopy (FESEM, Mira 3-XMU) was used to examine the morphologies and microstructures of the asprepared samples. Chemical compositions of prepared samples were confirmed by energy dispersive spectroscopy (EDX analyzer connected to FESEM instrument). The UV-Vis spectrophotometer (Shimadzu UV-1800) was used to determine the optical properties of and diffuse reflectance spectra (DRS) of samples.

\subsection{Photocatalytic Test}

The photocatalytic degradation of rhodamine $B(R h B)$, methylene orange (MO), and phenol was used to test the $\mathrm{Bi}_{2} \mathrm{MoO}_{6}$ photocatalytic activity. Lighting was provided by $300 \mathrm{~W}$ Xenon lamp. The reaction vessel was $75 \mathrm{~mL}$ beaker, with a distance of $12 \mathrm{~cm}$ between the lamp and the solution. The following experiment was achieved at room temperature: In a $50 \mathrm{~mL} R \mathrm{Rh}$ or MO solution, $0.05 \mathrm{~g}$ from catalyst was added. The suspensions were magnetically stirred in the dark for a 30 min before illumination to establish adsorption/desorption equilibrium between photocatalyst particles and RhB or MO. $2 \mathrm{~mL}$ sample was taken at predetermined and centrifuged intervals to remove photocatalyst particles. The variation of the absorption band maximum was recorded using a UV-Vis spectrophotometer (Shimadzu UV-1800) to determine the absorption band maximum. The concentrations variation of $\mathrm{RhB}$ and $\mathrm{MO}$ was obtained according to the linear relation between the absorbance at $555 \mathrm{~nm}$ and $465 \mathrm{~nm}$, respectively. The phenol was degraded also by using a $300 \mathrm{~W}$ xenon lamp with an irradiation wavelength of $>300 \mathrm{~nm}$. In $60 \mathrm{~mL}$ of phenol solution $\left(20 \mathrm{mgL}^{-1}\right), 0.1 \mathrm{~g}$ of photocatalyst was added. To achieve the adsorption-desorption equilibrium between the photocatalyst and phenol, the solution was magnetically stirred in the dark for a 30 min before illumination. A Shimadzu UV-1800 spectrophotometer was then used to record the adsorption spectrum of the centrifuged solution. The linear relationship between the absorbance and the concentration of phenol was used to determine the absorbance in phenol concentration (at $271 \mathrm{~nm}$ ).

\section{Results And Discussion}

\subsection{Structural properties}

The early $\mathrm{pH}$ values of the precursor solutions are well recognized to play a role in the production of the Aurivillius oxide $\mathrm{Bi}_{2} \mathrm{MoO}_{6}$ structure. As a result, several values of $\mathrm{pH}$ solutions were used in the current synthesis. $\mathrm{Bi}_{2} \mathrm{MoO}_{6}$, $\mathrm{Bi}_{2} \mathrm{MoO}_{6} / \mathrm{Bi}_{4} \mathrm{MoO}_{9}$ composites, and $\mathrm{Bi}_{4} \mathrm{MoO}_{9}$ are the three main compositions resulted in the samples synthesized at $\mathrm{pH}$ levels ranging from 2 to 10 . As shown in Fig. 1, low pH contributes to the production of orthorhombic $\mathrm{Bi}_{2} \mathrm{MoO}_{6}$ structure, 
medium $\mathrm{pH}$ to mixed phase of orthorhombic $\mathrm{Bi}_{2} \mathrm{MoO}_{6}$ and cubic $\mathrm{Bi}_{4} \mathrm{MoO}_{9}$ structures, and high pH contributes to the creation of cubic $\mathrm{Bi}_{4} \mathrm{MoO}_{9}$ structure. At pH $=2$ and 4 , the XRD pattern of the as-prepared product was indexed as $\mathrm{Bi}_{2} \mathrm{MoO}_{6}$. The XRD patterns also show a large change in relative intensities for the samples, all of the diffraction peaks can be indexed to phase of to (JCPDS card no. 21-0102). As shown in Fig. 1, the XRD patterns showed mixed phases of $\mathrm{Bi}_{2} \mathrm{MoO}_{6}$ (JCPDS card no. 21-0102) and cubic $\mathrm{Bi}_{4} \mathrm{MoO}_{9}$ (JCPDS card no.12-0149) when the $\mathrm{pH}$ was between 6 and 8 . When the $\mathrm{pH}$ is raised to 0 , the XRD pattern shows a pure cubic $\mathrm{Bi}_{4} \mathrm{MoO}_{9}$ without any evidence of the $\mathrm{Bi}_{2} \mathrm{MoO}_{6}$ phase. Based on these findings, it can be deduced that an acidic environment favors the formation of $\mathrm{Bi}_{2} \mathrm{MoO}_{6}$ whereas an alkaline environment favors the development of $\mathrm{Bi}_{4} \mathrm{MoO}_{9}$.

\subsection{Morphological properties}

FESEM images for $\mathrm{Bi}_{2} \mathrm{MoO}_{6}$ catalysts are shown in Fig. $2(\mathrm{a}, \mathrm{b})$. As can be seen, the samples synthesized at low $\mathrm{pH}=2,4$ values show a morphology of nano-plates like structure with different sizes and shapes in each sample. The plates of the samples generated under acidic $\mathrm{pH}$ were smooth and ranging between 100 and $250 \mathrm{~nm}$. Besides, the inset FESEM images of high magnification demonstrated more near view of individual plate and revealed the formation of packed square nanoplate with their thickness of about 40-60 nanometers and average length 100 and $250 \mathrm{~nm}$ as shown in inset Fig. 2 (a,b).

The higher $\mathrm{pH}$ value, result in formation smaller and spherical nanoparticles, which causes the higher surface area while the nanoplates gradually disappeared as illustrated in schematic Fig. 3. In samples pH=6-10, agglomerated formed of large number of nanospheres or spherical nanoparticles with the diameter range 35-90 nm as shown in Fig. 2 (inset c and d). The surface of spherical nanoparticles is mostly regular. This morphology changes in response to different values of $\mathrm{pH}$ and are linked to the kinetics of crystal nucleation and growth, which is influenced by the surface free energy. The preferential adsorption of molecules and ions, stimulates the formation of nanoparticles in varied shapes and compositions, affecting the catalyst morphology [22]. Based on the results, it suggests that the amount of $O$ atoms on the (010) plane was increased with increasing $\mathrm{pH}$ values. The hydrogen ions preferred to adsorb on the (010) planes related to high density of $\mathrm{O}$ atoms which resulted to slow down the crystal growth alone (010) plane and forming spherical nanoparticles [23,24]. The EDS mapping results as shown in table (1), reveal the distribution of Bismuth, Molybdate and Oxygen elements in the synthesized $\mathrm{Bi}_{2} \mathrm{MoO}_{6} \mathrm{NPs}$ at different $\mathrm{pH}$ values. The solvent may be one important factor in the synthesis process and can be used to precisely control the morphology and therefore affected by EDS results [25]. Therefore, in this work, the $\mathrm{HNO}_{3}$ acid is introduced in the preparation method of $\mathrm{Bi}_{2} \mathrm{MoO}_{6} \mathrm{NPs}$ and the role of $\mathrm{NaOH}$ solution to control on pH samples prepared. However, the percentage of $\mathrm{Bi}, \mathrm{Mo}$ and $\mathrm{O}$ elements varied in each sample, where All results provide successful increasing $\mathrm{Bi}$ element with increasing $\mathrm{pH}$ values a result of adding the amount of $\mathrm{NaOH}$ solution.

\subsection{Optical properties}

Figure 4 displays UV-visible absorption spectra of $\mathrm{Bi}_{2} \mathrm{MoO}_{6}$ samples $(\mathrm{pH} 2,4,6,8$ and 10), which have strong absorption properties ranging from ultraviolet to visible light with the wavelength being shorter than $450 \mathrm{~nm}$. The intrinsic energy gap transition of $\mathrm{Bi}_{2} \mathrm{MoO}_{6}$ extending from the valence band of the $02 \mathrm{p}$ orbitals to the conduction band obtained from the main Mo $4 \mathrm{~d}$ orbitals in $\mathrm{MoO}_{6}$ octahedrons and the secondary $\mathrm{Bi} 6 \mathrm{p}$ orbitals corresponds to the shape of the absorption edge [17]. With the $\mathrm{pH}$ value increasing from 2 to 10 , a slight red shift of the absorption band edge of $\mathrm{Bi}_{2} \mathrm{MoO}_{6}$ samples (from 2.55 to $2.87 \mathrm{eV}$ ) can be noticed in this system. The band gap energy of semiconductor nanoparticles is widely known to grow as grain size decreases. $\mathrm{Bi}_{2} \mathrm{MoO}_{6}$ with a nanostructure of samples produced at pH 6, $\mathrm{pH}$ 8, and pH 10 ( Eg equal 2.72, 2.88 and $2.87 \mathrm{eV}$, respectively) displayed a red shift in the band-gap transition when compared to $\mathrm{Bi}_{2} \mathrm{MoO}_{6}$ samples produced at $\mathrm{pH} 2$, and $\mathrm{pH} 4$ ( Eg equal 2.55 and $2.65 \mathrm{eV}$, respectively) with a nanostructure

\subsection{Photocatalytic activities of the catalysts}




\subsubsection{Photodegradation of RhB and MO under simulated solar light irradiation}

Both RhB and MO, which have a major absorption band at wavelength $₫=555 \mathrm{~nm}$ and $465 \mathrm{~nm}$, respectively, are chosen as a model organics contaminant to evaluate the photocatalytic activity of the hydrothermally produced materials $\left(\mathrm{Bi}_{2} \mathrm{MoO}_{6}\right)$ at $\mathrm{pH}$ from 2 to 10 values. When the time irradiation was increased, a strong absorption peak of RhB solution at $\nabla=555 \mathrm{~nm}$ gradually dropped and indicated a blue-shift to $\nabla=499 \mathrm{~nm}$ of $\mathrm{RhB}[2,26]$, Whereas, the $\mathrm{MO}$ gradually decreased and indicated a blue shift at $\nabla=456 \mathrm{~nm}$. Under visible-light irradiation with photocatalyst, RhB and $\mathrm{MO}$ are mineralize hazardous pollutants to harmless materials $[2,26,27]$.

Figure 5 (a) shows the photodegradation efficiency of the $\mathrm{Bi}_{2} \mathrm{MoO}_{6}$ photocatalyst when exposed to visible light, where it catalyst exhibits photocatalytic activity for the breakdown of $\mathrm{RhB}$ when exposed to visible light. The maximum activity is found in the $\mathrm{Bi}_{2} \mathrm{MoO}_{6}$ samples generated at $\mathrm{pH} 2$ and $\mathrm{pH}$ 4. Within 10 minutes of visible-light irradiation, the RhB photodegradation efficiency of $\mathrm{Bi}_{2} \mathrm{MoO}_{6}$ samples $\mathrm{pH} 2$ and 4 is $100 \%$. However, the activity of the $\mathrm{Bi}_{2} \mathrm{MoO}_{6}$ samples synthesized at $\mathrm{pH} 6,8$ and 10 were over $87 \%, 66 \%$ and $73 \%$, respectively.

In Fig. 5 (b), show the efficiency of the photodegradation efficiency, the $\mathrm{Bi}_{2} \mathrm{MoO}_{6}$ photocatalyst exhibits photocatalytic activity for the breakdown of the $\mathrm{MO}$ when exposed to visible light for certain periods. $\mathrm{Bi}_{2} \mathrm{MoO}_{6}$ sample prepared at $\mathrm{pH} 4$ have the highest activity. The photodegradation efficiency of $\mathrm{Bi}_{2} \mathrm{MoO}_{6}$ sample pH 4 is $99 \%$ after 210 min of visible-light irradiation. $\mathrm{Bi}_{2} \mathrm{MoO}_{6}$ samples produced at $\mathrm{pH} 2,6,8$, and 10 had activity of over $94 \%, 30 \%, 2 \%$ and $45 \%$, respectively.

By linear converting $\left[-\ln \left(\mathrm{C} / \mathrm{C}_{0}\right)=\mathrm{Kt}+\mathrm{a}\right], \mathrm{RhB}$ and $\mathrm{MO}$ are degraded in accordance with pseudo-first-order kinetics, where $\mathrm{k}$ denotes the apparent reaction rate constant, $\mathrm{C}_{0}$ denotes the initial concentration, and $\mathrm{C}$ is the concentration at time $t$. Because the concentration $(\mathrm{C})$ of $\mathrm{RhB}$ or $\mathrm{MO}$ has a linear relationship with the absorbance $(\mathrm{A})$, the above equation can be approximated to $-\ln \left(A / A_{0}\right)=k t+a$, which is consistent with first-order kinetics and supported by a nearly linear plot of $\ln \left(C_{C} C_{0}\right)$ with t. Figure $5(b)$ and $(d)$ show the kinetics charts and the related kinetics constants. At 0.2249 and 0.01091 min $^{-}$

1 , the kinetics constant for $\mathrm{Bi}_{2} \mathrm{MoO}_{6}$ produced at $\mathrm{pH} 4$ is the highest for $\mathrm{RhB}$ and $\mathrm{MO}$, respectively.

\subsubsection{Photodegradation of phenol under simulated solar light irradiation}

The most commonly utilized model pollutant in the study of photocatalytic activity is dyes. Previous investigations have demonstrated that dyes absorb visible light and can be destroyed via a sensitization mechanism in the presence of photocatalysts (Yan, Ohno et al. 2006, Al-keisy, Ren et al. 2016). As a result, in addition to the dye decolorization, we chose phenol as the model pollutant in our studies, as it has no light absorption properties in the visible spectrum region and no photosensitization impact, allowing us to better reflect the true contribution of photocatalysis. The photodegradation efficiencies of phenol as a function of irradiation duration using $\mathrm{Bi}_{2} \mathrm{MoO}_{6}$ catalysts (at $\mathrm{pH} 2,4,6,8$, and 10) under simulated visible light irradiation $(\lambda>300 \mathrm{~nm})$ are shown in Fig. 6 (a). The photodegradation effectiveness of pH 4 was highly compare to that of other samples, which could decompose $88 \%$ of the phenol after 300 minutes, however, the activity of the $\mathrm{Bi}_{2} \mathrm{MoO}_{6}$ samples synthesized at $\mathrm{pH} 2,6,8$ and 10 were over 75\%,68\%,29\% and 65\%, respectively. Furthermore, as shown in Fig. 6 (b), the equivalent results of reaction kinetics investigations show that $\mathrm{Bi}_{2} \mathrm{MoO}_{6}$ has a significantly higher photodegradation rate constant $(\mathrm{k})$ which is equal $0.00856 \mathrm{~min}^{-1}$. The comparison was conducted as shown in Fig. 7 Percentage mineralization, decolourisation of dyes over $\mathrm{Bi}_{2} \mathrm{MoO}_{6}$. The highest performance was indicated by $\mathrm{pH} 4$ and then $\mathrm{pH} 2$ while lower activity in $\mathrm{pH} 6, \mathrm{pH} 8$ and $\mathrm{pH} 10$.

\subsection{Photocatalytic activity mechanism}


On the basis of previous works, the possible mechanism was proposed based on the photocatalytic degradation of organic pollutants by $\mathrm{Bi}_{2} \mathrm{MoO}_{6}[1,2,14-21]$. Figure 8 shows a proposed photocatalytic reaction process for the degradation of organic dyes using $\mathrm{Bi}_{2} \mathrm{MoO}_{6}$ photocatalyst. When the photocatalyst in solution containing organic pollutants exposed to visible light, form electron-hole pairs. The electrons diffused to the $\mathrm{Bi}_{2} \mathrm{MoO}_{6}$ surfaces from the activated chemisorbed organic molecules, where they were instantly released into the conduction band of $\mathrm{Bi}_{2} \mathrm{MoO}_{6}$ to form $\mathrm{BMO}\left(\mathrm{e}_{\mathrm{CB}}{ }^{-}\right)$and then interacted with the surface adsorbed oxygen to form ${ }^{\circ} \mathrm{O}_{2 \rrbracket}$ oxygen superoxide radicals while $\mathrm{BMO}\left(\mathrm{h}_{\mathrm{VB}}{ }^{+}\right)$formed $\cdot \mathrm{OH}$ radicals when it came into contact with water molecules and/or hydroxyl ions. After that, both radicals ${ }^{\circ} \mathrm{O}_{2 \rrbracket}$ and $\cdot \mathrm{OH}$ are strong reducing and oxidizing agents respectively to decompose the organic dye.

The photocurrent response in photoelectochemical experiments can be used to monitor the generation and transfer of photoexcited charge carriers and understand the photocatalyst's interfacial charge transfer dynamics(Kim, Borse et al. 2005, Al-Keisy, Ren et al. 2019). The electrical interaction of $\mathrm{Bi}_{2} \mathrm{MoO}_{6}$ was then investigated using photoelectrochemical experiments at various $\mathrm{pH}$ levels. $\mathrm{Bi}_{2} \mathrm{MoO}_{6}$ photocurrent measurements were performed at $\mathrm{pH} 2,4,6,8$, and 10 . In all of the electrodes, a quick photocurrent densities response can be seen for each switch-on and switch-off event, as shown in Fig. 9

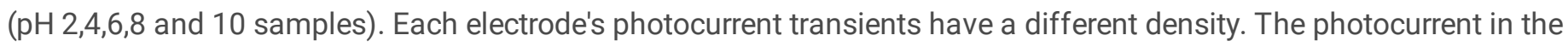
samples at the $\mathrm{pH} 2$ and 4 electrodes is significantly higher than in the other samples. Furthermore, the photocurrent of the samples at pH 2 and 4 electrodes is approximately three times that of the sample at pH 6 electrode and four times that of the sample at $\mathrm{pH}$ 8. Also, the photocurrent of the samples at $\mathrm{pH} 2$ and 4 electrodes is approximately five times that of the sample at pH 10 electrode. As a result, layer crystal structure which form nanoplates has higher spatial charge separation compare with nanoparticles form due to the layer structure has different sites of valence and conduction band (Al-Keisy, Ren et al. 2019). Under light irradiation, the photocurrent amplitudes of the two samples, pH 2 and 4 electrodes, are in good agreement with the photocatalytic activity.

\section{Conclusions}

The $\mathrm{Bi}_{2} \mathrm{MoO}_{6}$ samples prepared by the hydrothermal technique at $180^{\circ} \mathrm{C}$ for 15 hours. The optimal pH for the production of orthorhombic $\mathrm{Bi}_{2} \mathrm{MoO}_{6}$ nanoplates was found to be between 2,4 and 6, based on several characterization procedures. When all samples were compared, the sample synthesized at $\mathrm{pH} 4$ had the highest rate of $\mathrm{RhB}, \mathrm{MO}$, and phenol degradation, where was $100 \%$ within 10 min, $99 \%$ within 210 min and $88 \%$ within 300 min, respectively.

\section{Declarations}

\section{Acknowledgments}

The authors thank the applied science department and Nanotechnology and Advanced Materials Research Center, University of Technology/Baghdad-Iraq, particularly, SEM, UV-VIS and XRD for free access laboratory .

\section{Author contribution}

HN prepared the photocatalyst and test photocatalytic activity, AA wrote and edited some parts of manuscript and supervision, DA planed and supervision the research, AT tested the XRD and analyzed, AK wrote a part in manuscript. All authors read and approved the final manuscript.

\section{Funding}

This work was financially supported by Ministry of high education scientific researches of Iraq/Research and development department/Project management department. 
The datasets used and/or analyzed during the current study are available from the corresponding author on reasonable request.

Ethics approval and consent to participate Not applicable.

Consent for publication Not applicable.

Competing interests The authors declare no competing interests.

\section{References}

1. Al-keisy A, Ren L, Cui D, Xu Z, Xu X, Su X, Hao W, Dou SX, Du Y (2016) A ferroelectric photocatalyst $\mathrm{Ag}_{10} \mathrm{Si}_{4} \mathrm{O}_{13}$ with visible-light photooxidation properties. Journal of Materials Chemistry A 4(28):10992-10999

2. Al-Keisy A, Ren L, Xu X, Hao W, Dou SX, Du Y (2019) Selective Ferroelectric BiOl/ $\mathrm{Bi}_{4} \mathrm{Ti}_{3} \mathrm{O}_{12}$ Heterostructures for Visible Light-Driven Photocatalysis. J Phys Chem C 123(1):517-525

3. Asahi R, Morikawa T, Ohwaki T, Aoki K, Taga Y (2001) "Visible-Light Photocatalysis in Nitrogen-Doped Titanium Oxides" 293(5528):269-271

4. Dai Z, Qin F, Zhao H, Ding J, Liu Y, Chen R (2016) "Crystal Defect Engineering of Aurivillius $\mathrm{Bi}^{2} \mathrm{MoO}_{6}$ by Ce Doping for Increased Reactive Species Production in Photocatalysis". ACS Catalysis 6(5):3180-3192

5. Deng H, Wang J, Peng Q, Wang X, Li Y (2005) "Controlled Hydrothermal Synthesis of Bismuth Oxyhalide Nanobelts Nanotubes" 11(22):6519-6524

6. Du C, Yang L, Tan S, Song J, Zhang Z, Wang S, Xiong Y, Yu G, Chen H, Zhou L, Wu H, Liu Y (2021) "Reduced graphene oxide modified Z-scheme Agl/Bi2MoO6 heterojunctions with boosted photocatalytic activity for water treatment originated from the efficient charge pairs partition and migration. "Environmental Science and Pollution Research

7. Dumrongrojthanath $P$, Thongtem T, Phuruangrat A, Thongtem S (2015) Glycolthermal synthesis of $\mathrm{Bi}_{2} \mathrm{MoO}_{6}$ nanoplates and their photocatalytic performance. Mater Lett 154:180-183

8. Galván DH, Castillón FF, Gómez LA, Avalos-Borja M, Cota L, Fuentes S, Bartolo-Pérez P, Maple MB (1999) Influence of preparation on the structure and co conversion of $\mathrm{y}-\mathrm{Bi}_{2} \mathrm{MoO}_{6}$ catalysts. React Kinet Catal Lett 67(1):205-211

9. Guo Q, Zhou C, Ma Z, Yang X (2019) "Fundamentals of $\mathrm{TiO}_{2}$ Photocatalysis: Concepts. Mechanisms Challenges" 31(50):1901997

10. Guo S-q, Zhang X, Hao Z-w, Gao G-d, Li G, Liu L (2014) " $\mathrm{In}_{2} \mathrm{O}_{3}$ cubes: synthesis, characterization and photocatalytic properties". RSC Advances 4(59):31353-31361

11. Jin X, Ye L, Wang H, Su Y, Xie H, Zhong Z, Zhang H (2015) "Bismuth-rich strategy induced photocatalytic molecular oxygen activation properties of bismuth oxyhalogen: The case of $\mathrm{Bi}_{24} \mathrm{O}_{31} \mathrm{Cl}_{10}$ ". Appl Catal B 165:668-675

12. Kim HG, Borse PH, Choi W, Lee JS (2005) "Photocatalytic Nanodiodes for Visible-Light Photocatalysis" 44(29):45854589

13. Liang HY, Yang YX, Tang JC, Ge M (2013) Photocatalytic properties of $\mathrm{Bi}_{2} \mathrm{O}_{2} \mathrm{CO}_{3}$ nanosheets synthesized via a surfactant-assisted hydrothermal method. Mater Sci Semicond Process 16(6):1650-1654

14. Luo J, Steier L, Son M-K, Schreier M, Mayer MT, Grätzel M (2016) " $\mathrm{Cu}_{2} \mathrm{O}$ Nanowire Photocathodes for Efficient and Durable Solar Water Splitting. " Nano Letters 16(3):1848-1857

15. Madhusudan P, Yu J, Wang W, Cheng B, Liu G (2012) "Facile synthesis of novel hierarchical graphene $-\mathrm{Bi}_{2} \mathrm{O}_{2} \mathrm{CO}_{3}$ composites with enhanced photocatalytic performance under visible light". Dalton Trans 41(47):14345-14353

16. Meng X, Zhang Z (2017) $\mathrm{Bi}_{2} \mathrm{MoO}_{6}$ co-modified by reduced graphene oxide and palladium $\left(\mathrm{Pd}^{2+}\right.$ and $\left.\mathrm{Pd}^{0}\right)$ with enhanced photocatalytic decomposition of phenol. Appl Catal B 209:383-393 
17. Miao Y, Pan G, Huo Y, Li H (2013) Aerosol-spraying preparation of $\mathrm{Bi}_{2} \mathrm{MoO}_{6}$ : A visible photocatalyst in hollow microspheres with a porous outer shell and enhanced activity. Dyes Pigm 99(2):382-389

18. Nakata K, Fujishima A (2012) $\mathrm{TiO}_{2}$ photocatalysis: Design and applications. J Photochem Photobiol C 13(3):169-189

19. Peng Y, Ye G, Du Y, Zeng L, Hao J, Wang S, Zhou J (2021) $\mathrm{Fe}_{3} \mathrm{O}_{4}$ hollow nanospheres on graphene oxide as an efficient heterogeneous photo-Fenton catalyst for the advanced treatment of biotreated papermaking effluent. Environ Sci Pollut Res 28(29):39199-39209

20. Phuruangrat A, Jitrou P, Dumrongrojthanath $P$, Ekthammathat $N$, Kuntalue $B$, Thongtem S, Thongtem T (2013) Hydrothermal Synthesis and Characterization of $\mathrm{Bi}_{2} \mathrm{MoO}_{6}$ Nanoplates and Their Photocatalytic Activities. Journal of Nanomaterials 2013:789705

21. Phuruangrat A, Putdum S, Dumrongrojthanath $P$, Thongtem $S$, Thongtem $T$ (2015) Hydrothermal Synthesis of $B_{2} M_{0} O_{6}$ Visible-Light-Driven Photocatalyst. Journal of Nanomaterials 2015:135735

22. Rahman MF, Haque MS, Hasan M, Hakim MA (2019) Fabrication of Bismuth Vanadate $\left(\mathrm{BiVO}_{4}\right)$ Nanoparticles by a Facile Route. Trans Electr Electron Mater 20(6):522-529

23. Ramasamy B, Jeyadharmarajan J, Chinnaiyan P (2021) Novel organic assisted Ag-ZnO photocatalyst for atenolol and acetaminophen photocatalytic degradation under visible radiation: performance and reaction mechanism. Environ Sci Pollut Res 28(29):39637-39647

24. Wang Y, Zheng M, Liu S, Wang Z (2016) Size Control and Growth Process Study of Au@Cu $\mathrm{O}_{2}$ Particles. Nanoscale Res Lett 11(1):390-390

25. Xiao X, Hu R, Liu C, Xing C, Qian C, Zuo X, Nan J, Wang L (2013) Facile large-scale synthesis of $\beta-\mathrm{Bi}_{2} \mathrm{O}_{3}$ nanospheres as a highly efficient photocatalyst for the degradation of acetaminophen under visible light irradiation. Appl Catal B 140141:433-443

26. Yan X, Ohno T, Nishijima K, Abe R, Ohtani B (2006) Is methylene blue an appropriate substrate for a photocatalytic activity test? A study with visible-light responsive titania. Chem Phys Lett 429(4):606-610

27. Zhang Z, Wang W, Yin W, Shang M, Wang L, Sun S (2010) "Inducing photocatalysis by visible light beyond the absorption edge: Effect of upconversion agent on the photocatalytic activity of $\mathrm{Bi}_{2} \mathrm{WO}_{6}{ }^{\prime \prime}$. Appl Catal $\mathrm{B}$ 101(1):68-73

28. Zhao J, Liu Z, Lu Q (2016) Electrospun 1D SiO 2 doped $\mathrm{Bi}_{2} \mathrm{MoO}_{6}$ microbelts for highly efficient photocatalytic applications. Dyes Pigm 134:553-561

\section{Table}

Table (1): EDS spectra of $\mathrm{Bi}_{2} \mathrm{MoO}_{6}$ samples at (a) pH 2, (b) pH 4, (c) pH 6, (d) $\mathrm{pH} 8$ and (f) $\mathrm{pH} 10$.

\begin{tabular}{|c|c|c|c|c|c|c|c|c|c|c|c|c|c|c|}
\hline \multicolumn{3}{|c|}{ pH 2} & \multicolumn{3}{|c|}{$\mathrm{pH} 4$} & \multicolumn{3}{|c|}{$\mathrm{pH} 6$} & \multicolumn{3}{|c|}{ pH 8} & \multicolumn{3}{|c|}{$\mathrm{pH} 10$} \\
\hline Elt $^{*}$ & W\% & At\%\# & Elt & W\% & At\% & Elt & W\% & At\% & Elt & W\% & At\% & Elt & W\% & At\% \\
\hline $\mathrm{Bi}$ & 60.91 & 17.08 & $\mathrm{Bi}$ & 36.26 & 4.90 & $\mathrm{Bi}$ & 64.43 & 20.39 & $\mathrm{Bi}$ & 65.58 & 20.24 & $\mathrm{Bi}$ & 82.23 & 33.79 \\
\hline Mo & 19.74 & 12.06 & Mo & 11.78 & 3.47 & Mo & 19.57 & 13.49 & Mo & 17.57 & 11.81 & Mo & 6.52 & 5.83 \\
\hline 0 & 19.35 & 70.86 & 0 & 51.96 & 91.63 & 0 & 16.00 & 66.13 & 0 & 16.85 & 67.95 & 0 & 11.25 & 60.38 \\
\hline
\end{tabular}

\footnotetext{
* Elements, At: atomic perecent, W\%: weight percent.
}

\section{Figures}




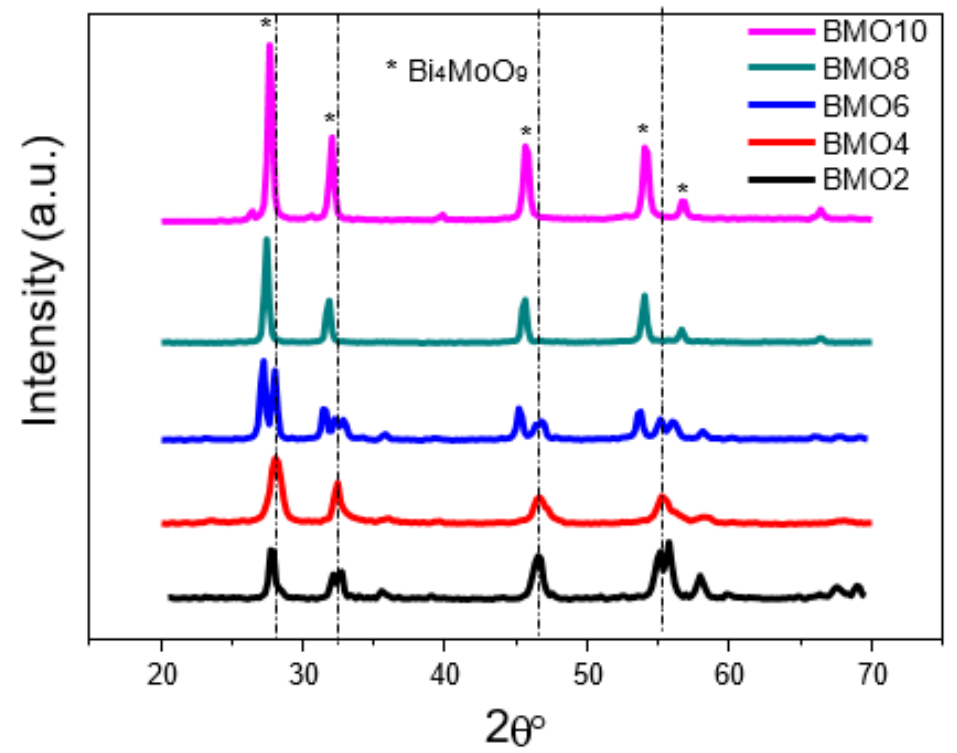

Figure 1

XRD patterns of the as prepared products.

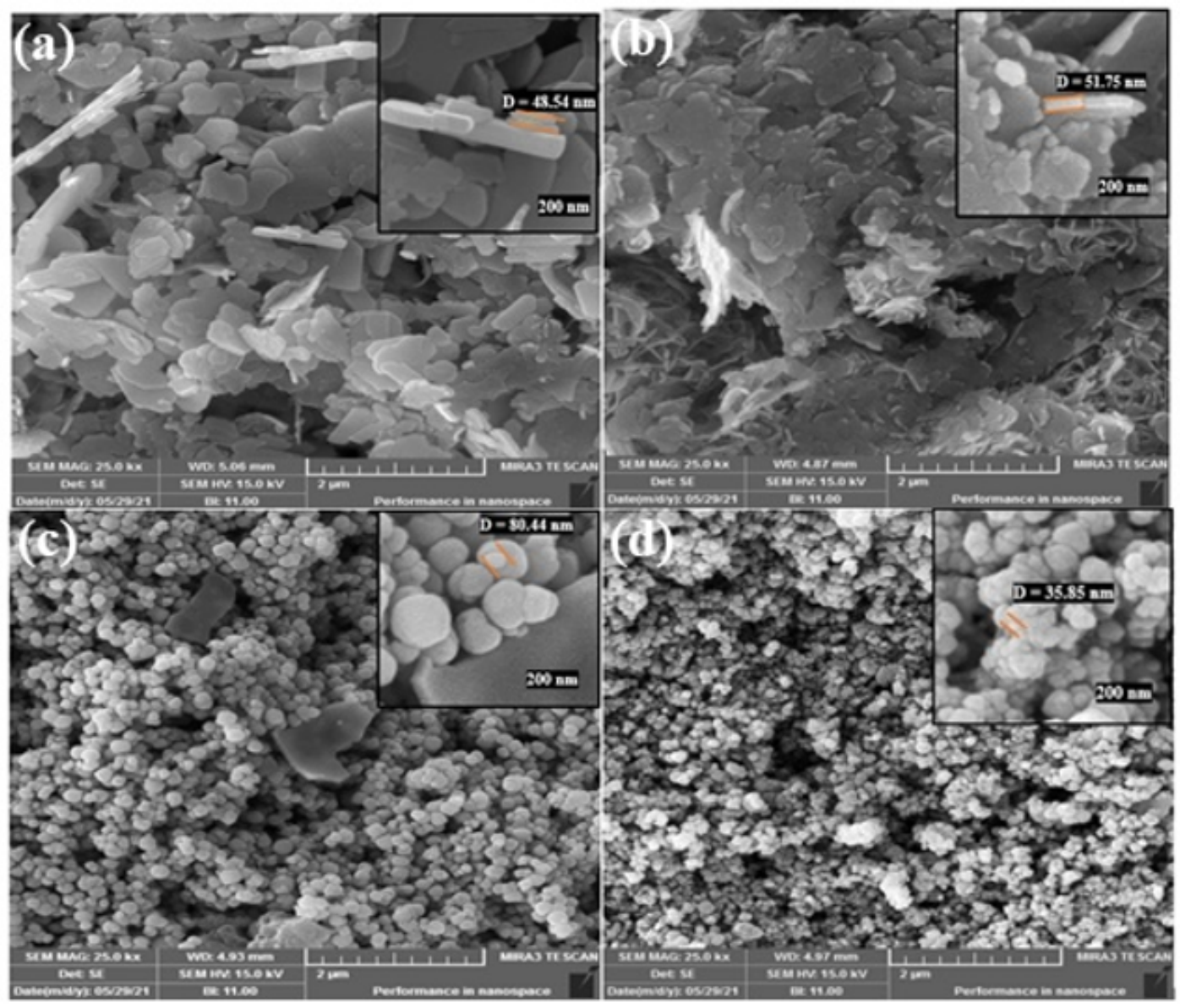

Figure 2

FESEM images of Bi2MoO6 samples at (a) $\mathrm{pH}$ 2, (b) $\mathrm{pH} 4$, (c) $\mathrm{pH}$ 6, and (d) $\mathrm{pH} 10$. 


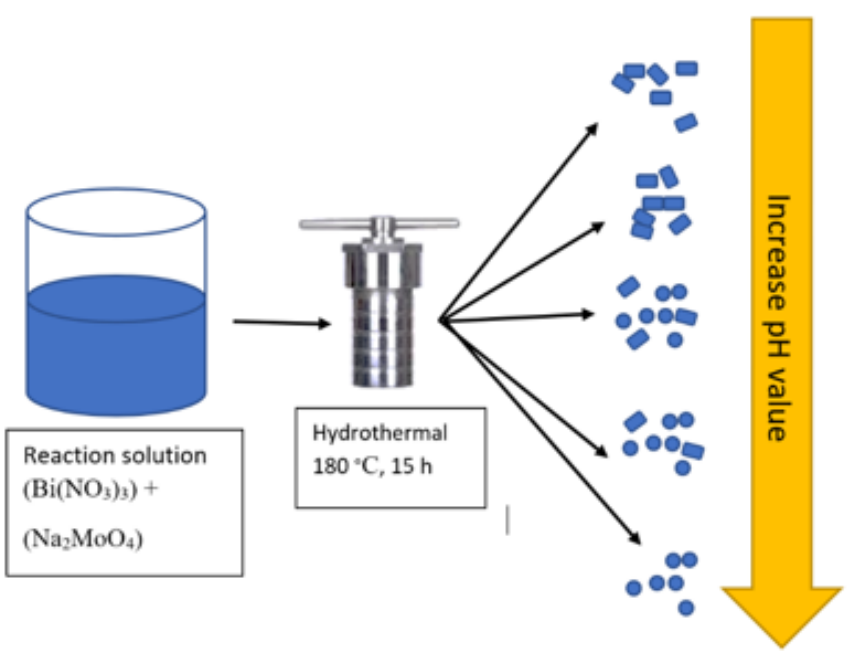

Figure 3

Schematic illustration of hydrothermal synthesis of the samples produced at $\mathrm{pH} 2,4,6,8$ and 10

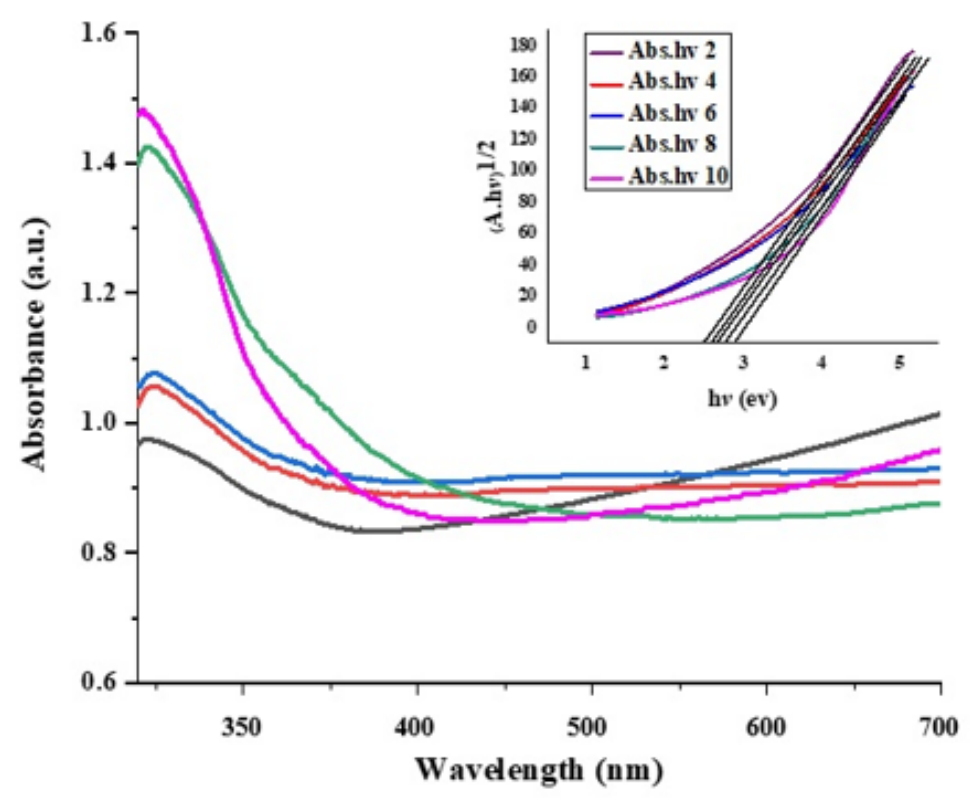

Figure 4

UV-vis diffuse reflection spectra (DRS) of the samples produced at $\mathrm{pH} 2,4,6,8$ and 10 

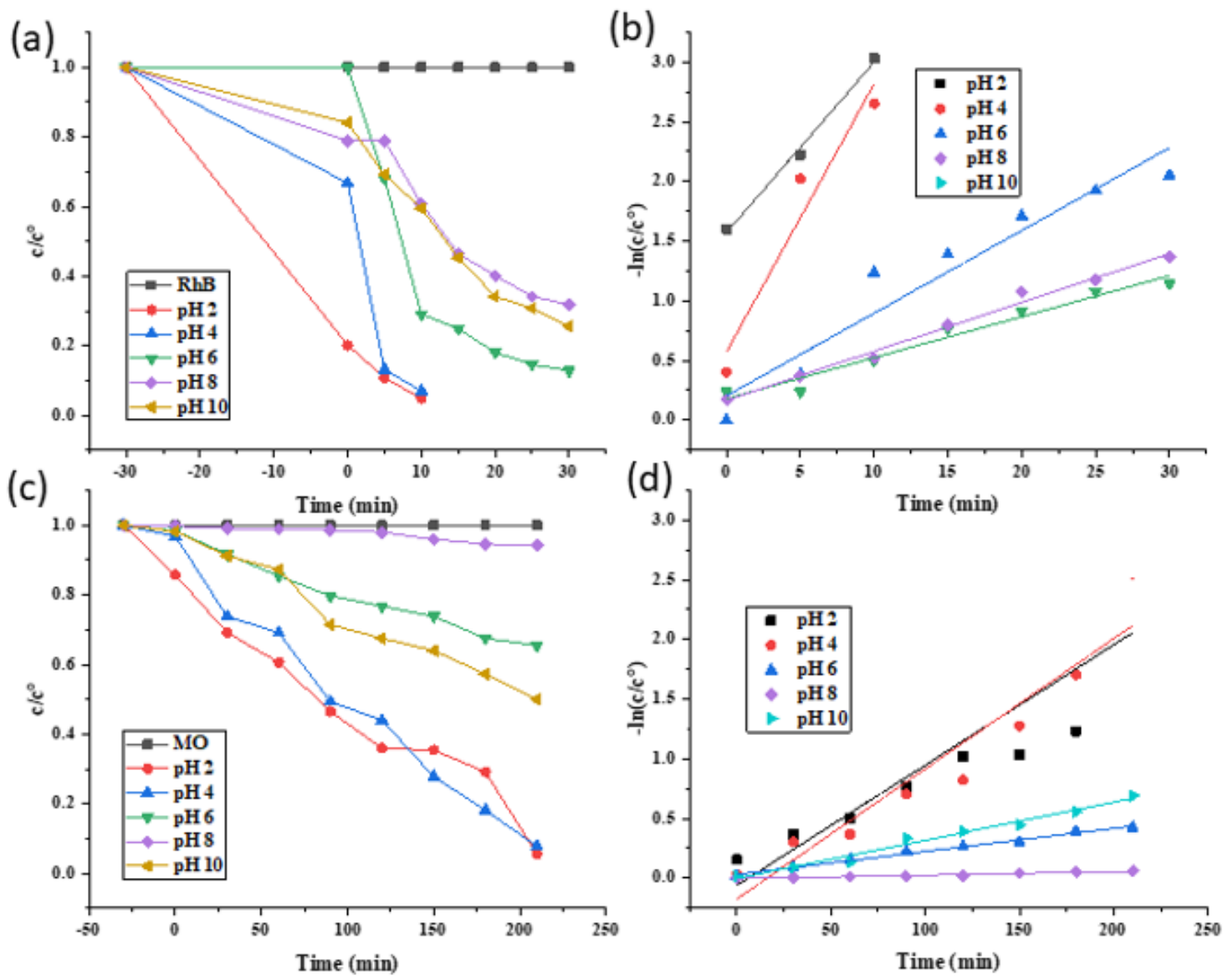

Figure 5

Photocatalytic degradation of (a) RhB over the samples prepared at time 30 min and (c) MO over the samples prepared at time 210 min under visible-light irradiation. Kinetic plots in the degradation of (b) RhB and (d) MO dyes over prepared catalysts.
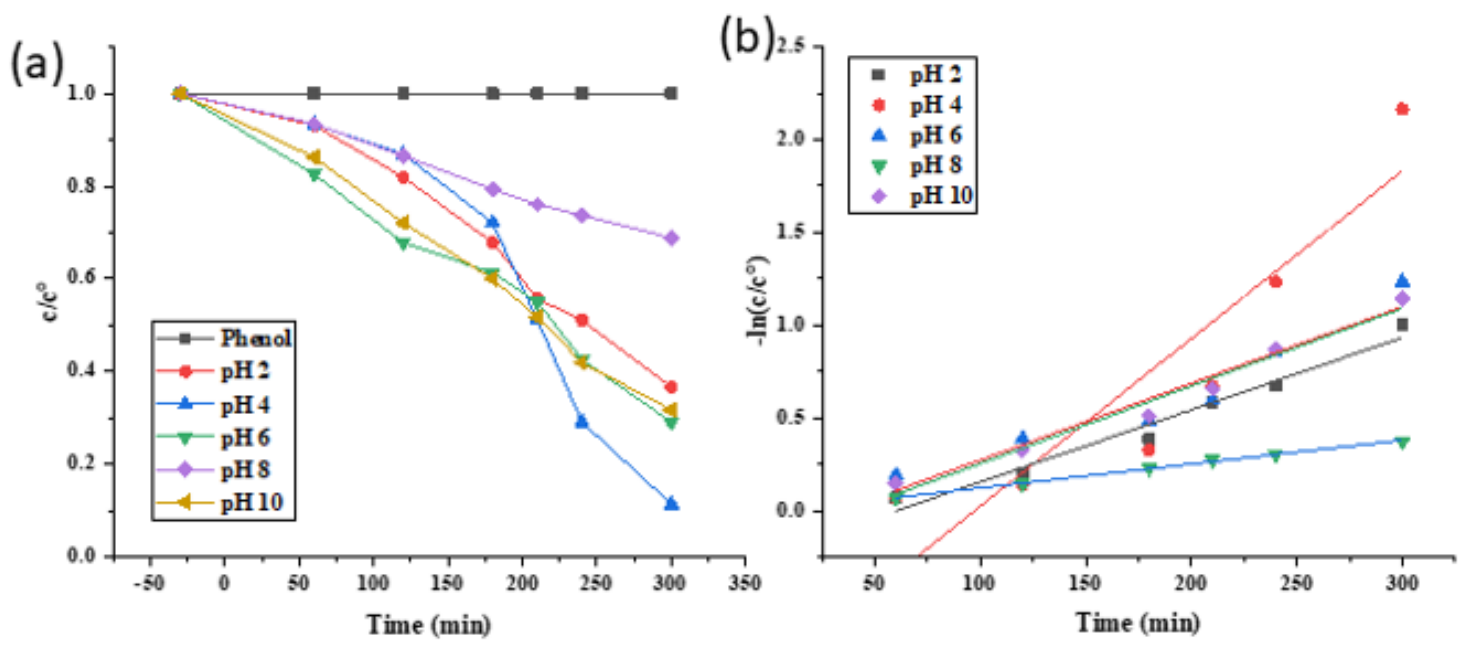

\section{Figure 6}

Photocatalytic degradation of phenol under simulated visible light irradiation. (a) degradation efficiency as a function of time by the as-prepared samples; (b) Kinetic plots in the degradation of as prepared catalysts. 


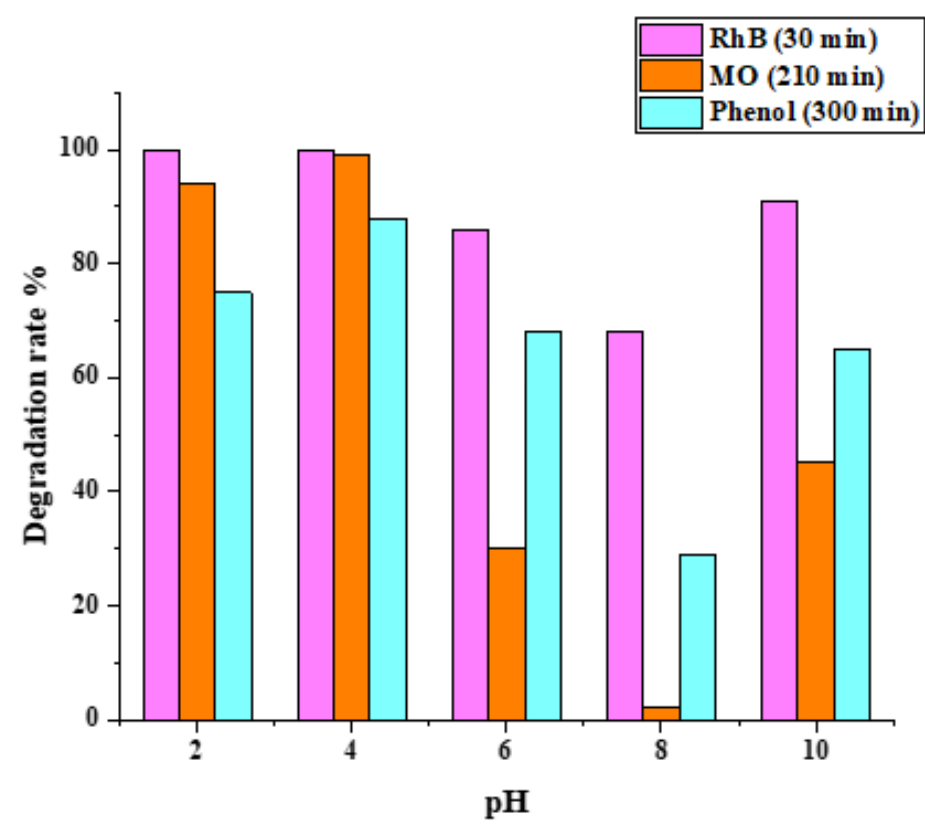

Figure 7

Percentage mineralization, decolourisation of dyes over Bi2MoO6.

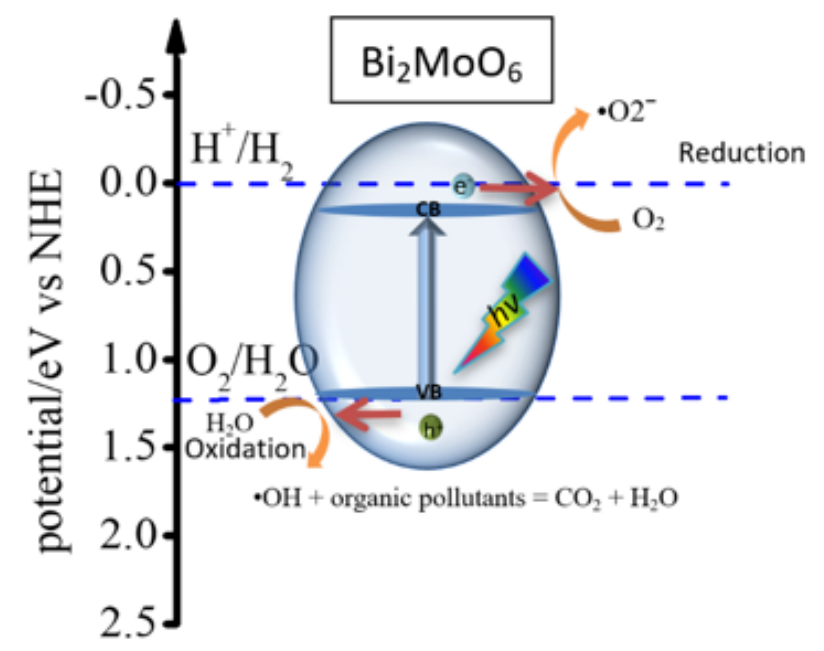

Figure 8

Possible photocatalytic mechanism of $\mathrm{Bi} 2 \mathrm{MoO} 6$ catalyst in the degradation of dyes. 


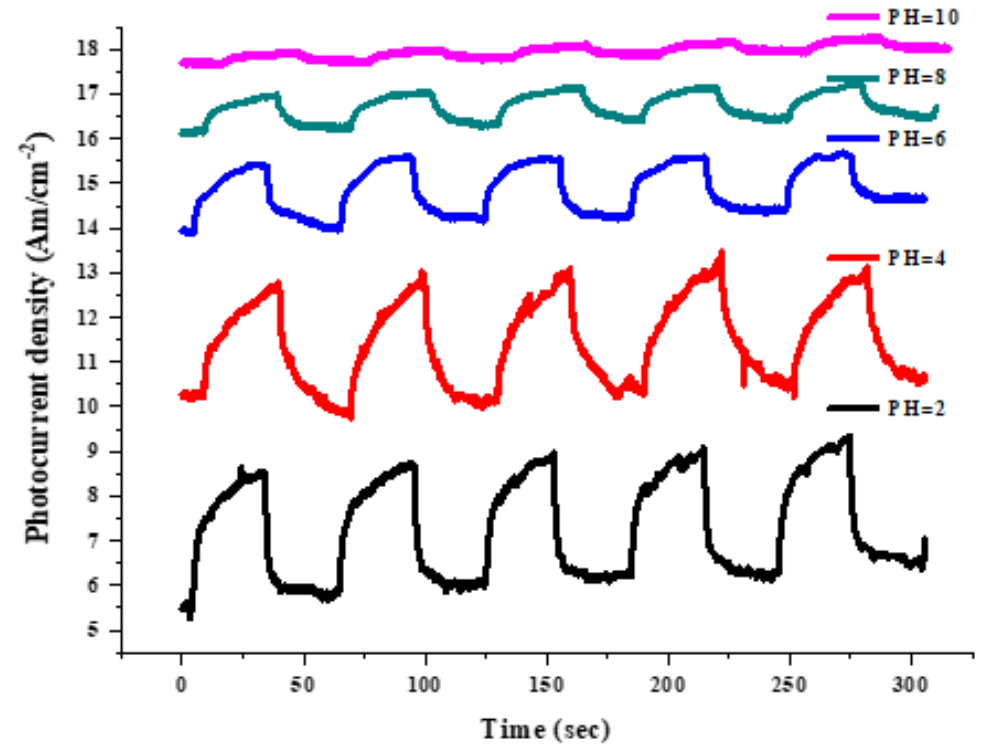

Figure 9

Photocurrent density responses of the $\mathrm{Bi} 2 \mathrm{MoO} 6$ at $\mathrm{pH} 2,4,6,8$, and 10 for five on - off at $0.5 \mathrm{~V} \mathrm{vs}$. Ag/ $\mathrm{AgCl}$ with visible light excitation. 